\title{
Effect of Ti on the Mechanical Properties and Corrosion of Cast AZ91 Magnesium Alloy
}

\author{
Xiulan $\mathrm{Ai}^{*}$ and Gaofeng Quan
}

Liaoning Province Laboratory of Key Material for Railway, Dalian Jiaotong University, Dalian 116028, China

\begin{abstract}
Ti addition to AZ91 alloy was been investigated with conventional casting. The microstructure and mechanical property were examined. The Corrosion resistance of all the different Ti addition content alloy was studied in $3.5 \% \mathrm{NaCl}$ solution through weight loss measurement in constant immersion conditions and potentiodynamic polarization experiments. The results show that addition of $\mathrm{Ti}$ with an amount of $0.1 \sim 0.5 \% \mathrm{wt}$ resulted in a refinement of the as-cast microstructure. The morphology of $\beta$ phases is changed from coarse, uneven, semi-continuous skeletal network to small, uniform, short rod-like or granular. When the content of $\mathrm{Ti}$ is $0.4 \mathrm{wt} \%$, the tensile strength and elongation go up to maximum value of $197 \mathrm{MPa}$ and $6.9 \%$ respectively. The corrosion resistant improved through addition Ti element is related to the morphology and distribute of $\beta$ phases. The mechanism of mechanical properties and corrosion resistant improvement caused by $\mathrm{Ti}$ addition is discussed.
\end{abstract}

Keywords: AZ91 magnesium alloy, Ti addition, Mechanical properties, Corrosion.

\section{INTRODUCTION}

As the most promising lightweight materials, magnesium alloys have high specific strength and specific stiffness, good yield strength, excellent machinability and good damping capacity. So, more and more magnesium alloy products have been used in automobile, aerospace and communication industries. AZ and AM series of alloys constitute about $90 \%$ of all structural applications of magnesium. AZ91D alloy has been used to fabricate a variety of automobile parts, such as cam covers, baffles, oil adapters, clutch housings, steering wheels, and so on; AM60 and AM50 alloys are frequently employed to manufacture instrument panels, steering wheel armatures, and seat risers. However, complex hard and brittle $\beta$ phases mostly formed at grain boundaries [1,2], they deteriorated the mechanical properties of magnesium alloys. At same time, corrosion limits the application of magnesium alloys $[3,4]$. Several studies $[5,6]$ have shown that the corrosion behavior is significantly influenced by microstructure, particularly the amount and distribution of the intermetallic phases $\beta-\mathrm{Mg}_{17} \mathrm{Al}_{12}$ (the following are called $\beta$ phases).

Ti element have excellent properties such as high corrosion resistance, good mechanical properties [7]. Our previous work showed $\mathrm{Ti}$ element could refine the as-cast microstructure and changed the morphology of $\beta$ phases. The present investigation is concentrated on studying the effect of Ti element on microstructure, mechanical properties and corrosion behavior of as-cast AZ91 alloys.

*Address correspondence to this author at the School of Materials Science and Engineering, Dalian Jiaotong University, Dalian 116028, China; Tel: +86411-84106852; Fax: +86-411-84106828;

E-mails: aixl@djtu.edu.cn, aixiulan@163.com

\section{EXPERIMENT PROCEDURES}

\subsection{Materials}

The compositions of four experimental alloys are designed as Table 1. The raw materials for the alloys are magnesium (99.8wt \%) ingots, aluminum (99.7wt \%) ingots, Zinc (99.8wt\%) ingots and $\mathrm{Al}-6 \mathrm{Ti}$ alloy ingots. Smelting processes were carried out in an $12 \mathrm{~kg}$ well crucible electric resistance furnace under condition of shielding RJ2. The ingots were melt completely, up to a temperature of $670^{\circ} \mathrm{C}$ the $\mathrm{Al}-6 \mathrm{Ti}$ alloy was added. When the temperature of the molten metal was raised to $750^{\circ} \mathrm{C}$, the melt was held for $20 \mathrm{~min}$ to make sure that $\mathrm{Ti}$ was completely dissolved. Afterwards the melt was poured into a preheated steel mould at approximately $720^{\circ} \mathrm{C}$. In this process the melt was stirred several times to ensure homogeneous distribution of $\mathrm{Ti}$ and other alloying elements. The base nominal composition of the alloys studied was $\mathrm{Mg}-9 \mathrm{Al}-0.8 \mathrm{Zn}-0.2 \mathrm{Mn}$ conformed to that of AZ91. The dimension of sample is $20 \mathrm{~mm} \times 20 \mathrm{~mm} \times 20 \mathrm{~mm}$.

Table 1. Chemical Compositions of the Alloys Studied (wt \%)

\begin{tabular}{|c|c|c|c|c|c|}
\hline \multirow{2}{*}{ Alloys } & \multicolumn{5}{|c|}{ Designed Compositions } \\
\cline { 2 - 6 } & Al & Zn & Mn & Ti & Mg \\
\hline \hline AZ91 & 9.0 & 0.8 & 0.2 & $/$ & Bal. \\
\hline AZ91-0.2Ti & 9.0 & 0.8 & 0.2 & 0.2 & Bal. \\
\hline AZ91-0.4Ti & 9.0 & 0.8 & 0.2 & 0.4 & Bal. \\
\hline AZ91-0.8Ti & 9.0 & 0.8 & 0.2 & 0.8 & Bal. \\
\hline
\end{tabular}

\subsection{Corrosive Medium}

The $3.5 \% \mathrm{NaCl}$ solution test medium was made with $\mathrm{AR}$ grade $\mathrm{NaCl}$ and distilled water. The $\mathrm{pH}$ value was controlled at 7-7.5. All corrosion tests were carried out at room temperature. 


\subsection{Constant Immersion Testing}

The specimens were ground on progressively finer emery papers up to 1000 grade and then polished using $1 \mu \mathrm{m}$ diamond paste. The polished and preweighed specimens were exposed to $400 \mathrm{ml}$ of $3.5 \% \mathrm{NaCl}$ solution for a constant time. The corroded specimens were immersed in a solution of $20 \mathrm{wt} \% \mathrm{CrO}_{3}+1 \mathrm{wt} \% \mathrm{AgNO}_{3}$ in $200 \mathrm{ml}$ of boiling water for 5 minutes at ambient temperature to remove the surface corrosion products and then were washed by flowing water, cleaned with acetone and absolute alcohol respectively for 2 min and cold dried again. The weight loss was subsequently measured by means of an electronic balance with a precision of $\pm 0.1 \mathrm{mg}$. The corrosion rate was calculated according to the following Eq. 1

$\mathrm{V}=(\mathrm{W} 1-\mathrm{W} 2) /(\mathrm{A} \times \mathrm{t})$

where $\mathrm{V}$ denotes the corrosion rate of the specimen, W1the weight before the corrosion, W2 the weight after the corrosion (wipping off the corrosion products), and A the surface area and $t$ the corrosion time. The experimental results were the mean value of three samples.

\subsection{Electrochemical Testing}

The specimens for electrochemical measurements, of dimensions $20 \mathrm{~mm} \times 20 \mathrm{~mm} \times 5 \mathrm{~mm}$, were polished to 1500 grit $\mathrm{SiC}$ paper and a copper wire was welded on the backsurface for electrical contact. The specimens were embedded with epoxy resin so that about $1 \mathrm{~cm}^{2}$ was exposed to the solution. The specimens were given a metallographic polish prior to each experiment, followed by washing with distilled water and acetone. Polarization measurements were carried out in a corrosion cell containing $400 \mathrm{ml}$ of $3.5 \%$ $\mathrm{NaCl}$ solution using a CHI660C electrochemical measurement system: saturated colomel as a reference with a platinum electrode as counter and the sample as the working electrode. Specimens were immersed in the $3.5 \% \mathrm{NaCl}$ solution. A polarisation scan was carried out from cathodic potential to anodic potential at a rate of $1 \mathrm{mV} \mathrm{s}^{-1}$, after allowing a steady state potential to develop.

\subsection{Microstructure and Surface Morphology}

The microstructure and surface morphology were observed by an Olympus- BX51M optical microscopy. Determination of crystalline structure of different phases in the alloys studied was carried out by energy dispersive X-ray diffraction (XRD). The morphology of phases was

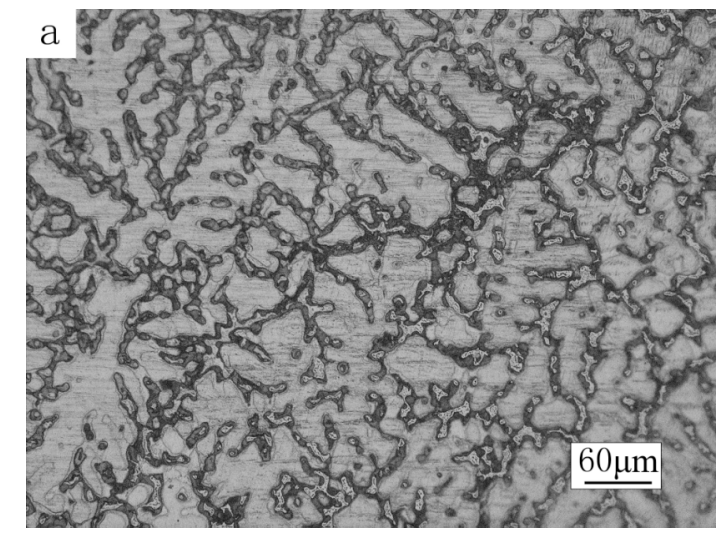

Fig. (1). As-cast microstructures of alloy AZ91 ( $\mathrm{Ti}=0 \mathrm{wt} \%)$. investigated by a JSM-6360LV scanning electron microscope (SEM) coupled with energy dispersed spectroscopy (EDS) system.

\subsection{Mechanical Properties Testing}

Tensile testing was performed using Instron5569 electron universal testing machine at room temperature (RT) with strain rate of $1.7 \times 10^{-3} \mathrm{~s}^{-1}$. Tensile specimens with gauge section of $35 \mathrm{~mm} \times 15 \mathrm{~mm} \times 3 \mathrm{~mm}$ were cut from the ingots prepared by electric spark machining.

\section{RESULTS AND DISCUSSION}

\subsection{Microstructures}

Fig. (1a) is an optical micrograph taken from the as-cast specimen of the alloy AZ91 showing coarse dendrites. SEM observations revealed that the microstructure of as-cast AZ91 was composed of $\alpha-\mathrm{Mg}$ matrix and two types of phases segregated on the boundaries of the $\alpha-\mathrm{Mg}$ dendrite structures. The first one was coarse with an irregular morphology. The second one was tiny laminar shaped surrounding the first one, as shown in Fig. (1b). According to the Mg-Al phase diagram and the previous investigations [8-11], these particles should be the $\beta-\mathrm{Mg}_{17} \mathrm{Al}_{12}$ phase. Small amount of Ti elements addition to the AZ91 alloy resulted in significant refinement of the as-cast microstructure, as shown in Figs. (2-4) and Table 2. When $0.8 \mathrm{wt} \% \mathrm{Ti}$ was added, it can be found that there are some bright, rod particles lying in grain and grain boundaries. According to the XRD results (Fig. 5), it can be confirmed that rod-like precipitates are $\mathrm{TiAl}_{3}$. However, compared to the AZ91 alloy, the other three alloys with a small amount of Ti added have finer grain sizes. These changes about the microstructure of AZ91 magnesium alloy can be analyzed from the following two aspects:

On the one hand, Ti element is surface-active element, so during the course of alloy solidification, it can significantly reduce the alloy solid - liquid interfacial tension. According to nucleation formula, see Eq. 2.

$$
r^{*}=\frac{-2 \sigma_{L S}}{\Delta G_{m}}
$$

where $\mathrm{r}^{*}$ is the critical nucleation radius, $\sigma_{\mathrm{LS}}$ solid-liquid interfacial tension and $\Delta \mathrm{G}_{\mathrm{m}}$ Gibbs free energy for the solidification reaction. Ti element reduces the critical

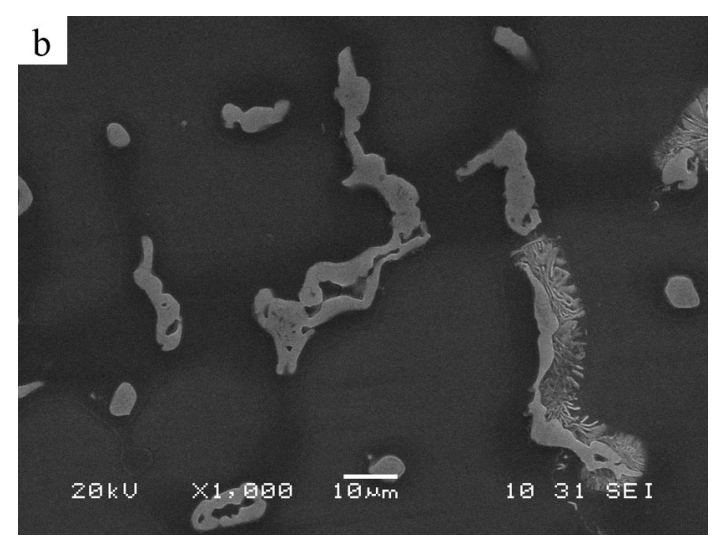




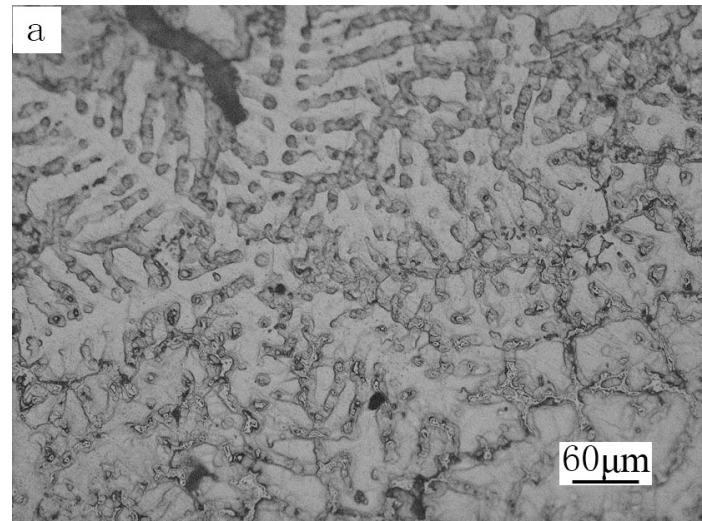

Fig. (2). As-cast microstructures of alloy $\mathrm{AZ} 91-0.2 \mathrm{Ti}(\mathrm{Ti}=0.2 \mathrm{wt} \%)$.

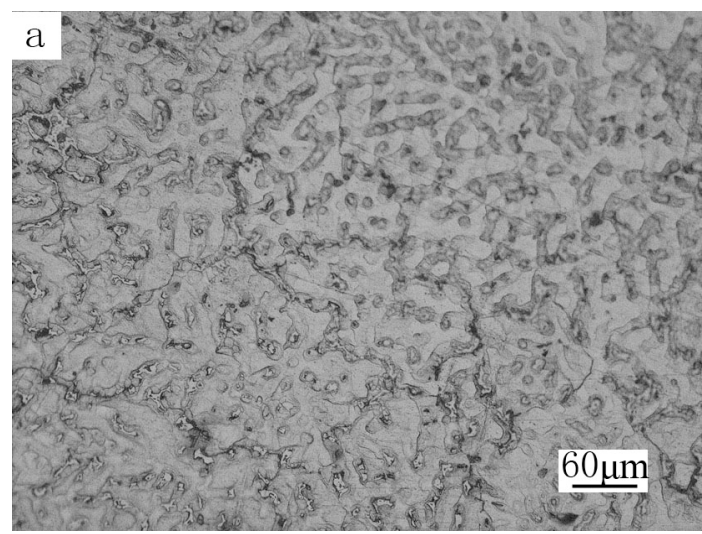

Fig. (3). As-cast microstructures of alloy AZ91-0.4Ti $(\mathrm{Ti}=0.4 \mathrm{wt} \%)$.

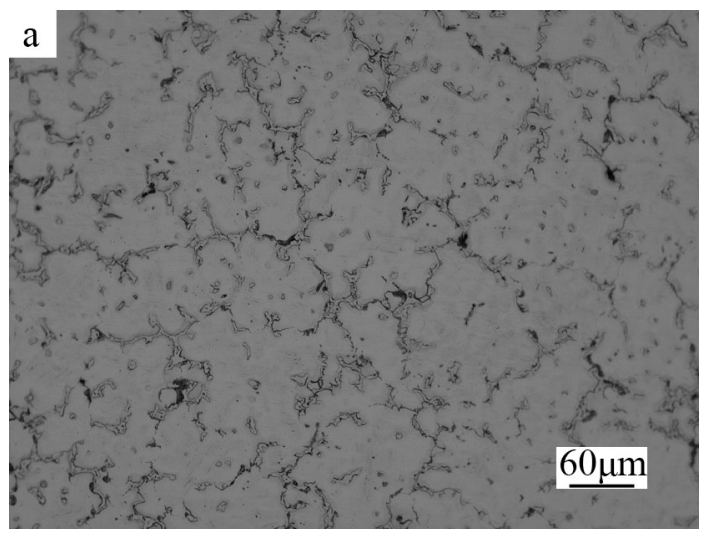

Fig. (4). As-cast microstructures of alloy A Z91-0.8Ti (Ti=0.8wt\%).

nucleation radius by reducing the liquid-solid interfacial tension, and the ultimately nuclear volume of the $\alpha-\mathrm{Mg}$ in the liquid phase is improved. Compared with the AZ91 magnesium alloy, under the same conditions of cooling rate, AZ91-Ti melt, during the initial solidification, has more $\alpha$ $\mathrm{Mg}$ nuclei which lead $\alpha-\mathrm{Mg}$ dendrite smaller. Furthermore, Ti adsorbed on the tip of growth $\beta$ phases, thus prevents them from growing up, and reduces their size. As results, the amount of $\beta$ phases on the grain boundaries become short and the dispersion degree of $\beta$ phases improves.

On the other hand, because the chemical action does not occur between $\mathrm{Ti}$ and $\mathrm{Mg}$ elements [12], Al elements and $\mathrm{Ti}$ elements combine to form intermetallic compounds rather than the combinations of $\mathrm{Mg}$ and $\mathrm{Ti}$ on the same condition. From the thermodynamic point of view, in the Mg-Al-Ti
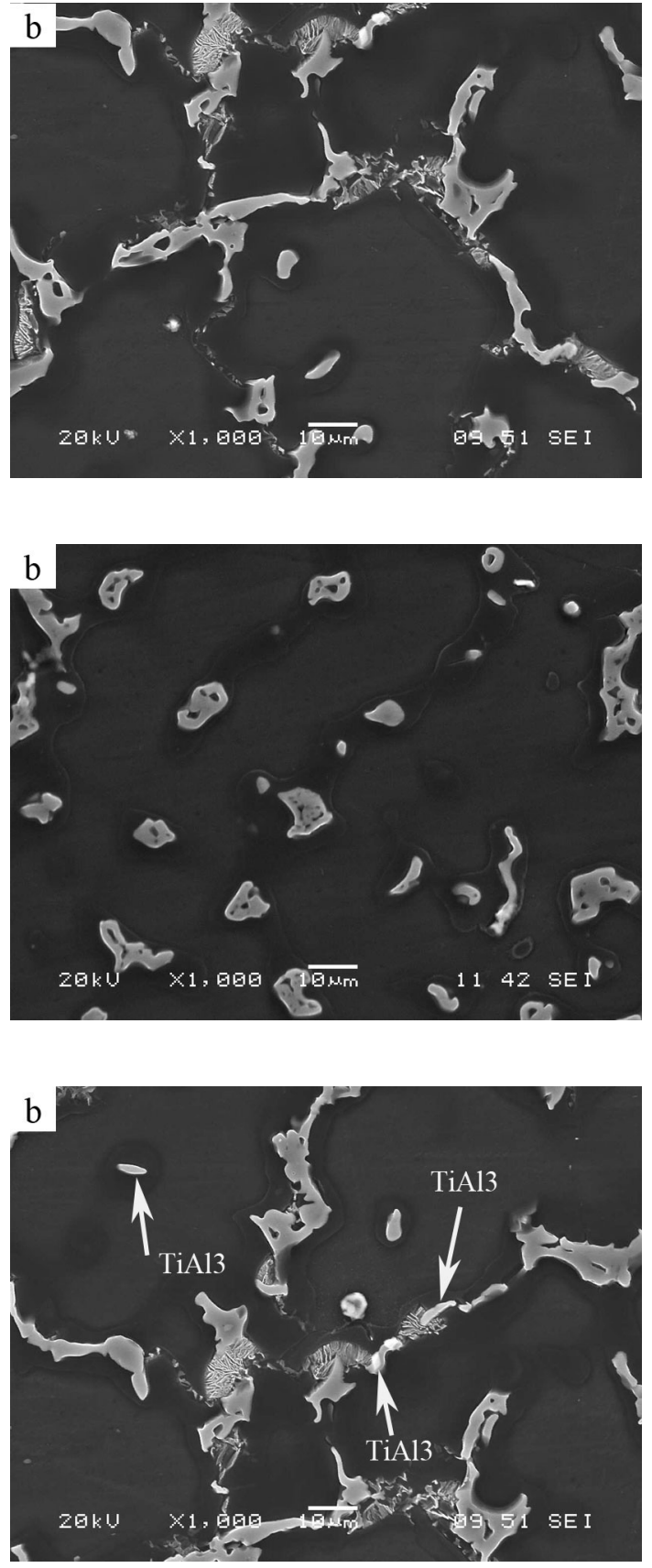

system, Al elements firstly combine with $\mathrm{Ti}$ elements to intermetallic compounds, while, the remaining Al elements combine with $\mathrm{Mg}$ elements to form the compounds, or solve in the $\mathrm{Mg}$ matrix $[13,14]$. Mostly, $\mathrm{Ti}$ elements and $\mathrm{Al}$ elements have the response to form AlTi or $\mathrm{TiAl}_{3}$ two kinds of intermetallic compounds. But from the perspective of thermodynamics, the reaction of producing intermetallic compounds $\mathrm{TiAl}_{3}$ is easier. In this alloy, $\mathrm{TiAl}_{3}$ distributes in the matrix and the second phases by cosh shape (Fig. 4b). Although Al-Ti compounds are not considered as the core of crystal formations, it can impede the growth of $\alpha-\mathrm{Mg}$ branch crystal. The reason is that with the growth of $\alpha-\mathrm{Mg}$ grains, Al-Ti compounds concentrate along the grain boundaries to prevent the grain growth, suppress Al elements spreading into the melt, to prevent $\beta$ phases formation and growth, to 
reduce the number of $\beta$ phases, Thus this provides a driving force to other nucleation particle in liquid in front of solidification for shaping core.

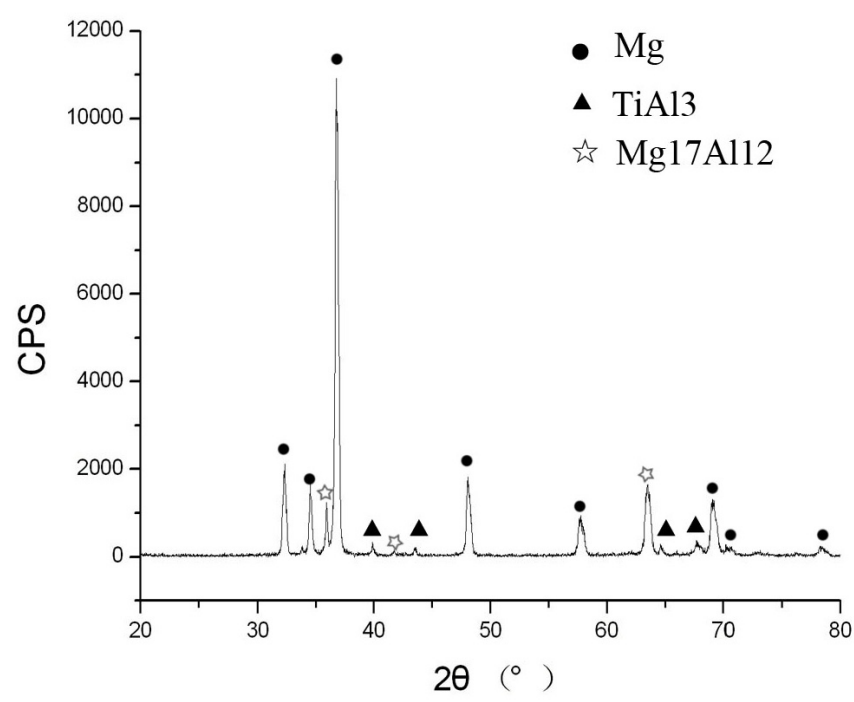

Fig. (5). X-ray diffraction pattern of AZ91-0.8Ti alloy.

Table 2. Structural Characteristic of AZ91 Magnesium Alloy at Different Ti Content

\begin{tabular}{|c|l|}
\hline $\begin{array}{c}\text { Ti Content } \\
\text { (wt. \%) }\end{array}$ & \multicolumn{1}{c|}{ Structure Characteristic } \\
\hline \hline 0 & $\begin{array}{l}\alpha \text {-Mg is dendritic, } \beta \text { - phases are irregular morphology } \\
\text { and laminar shaped }\end{array}$ \\
\hline 0.2 & $\begin{array}{l}\text { the amount of } \beta \text { phases particles in grain increased, } \\
\text { laminar shaped } \beta \text { phases are few and granular, } \\
\text { morphology } \beta \text { phases are coarse, uneven, semi- } \\
\text { continuous skeletal network }\end{array}$ \\
\hline 0.4 & $\begin{array}{l}\text { laminar shaped } \beta \text { phases are disappearance, morphology } \\
\beta \text { phase are small (about 10 } \mu \mathrm{m}), \text { uniform and } \\
\text { uncontinuous }\end{array}$ \\
\hline 0.8 & $\begin{array}{l}\text { microstructure became very thick again, the amount of } \\
\text { laminar shaped } \beta \text { phases are more, there are some bright } \\
\text { and rod particles lying in grain and grain boundaries }\end{array}$ \\
\hline
\end{tabular}

Third, with the increasing of Ti elements content, or the enriching of Ti elements on solid - liquid interface leadingedge, Ti elements and $\mathrm{Al}$ elements may form $\mathrm{TiAl}_{3}$ compounds. Their size and distribution are decided by $\mathrm{Ti}$ content. When the Ti content increases to a certain amount, $\mathrm{TiAl}_{3}$ is pushed to $\alpha-\mathrm{Mg}$ dendrite community by solid liquid interface and gathers in there. So, the refinement effect of $\alpha-\mathrm{Mg}$ and $\beta$ phases is weakened and the size of $\beta$ phases increase.

\subsection{Tensile Properties}

The mechanical properties including ultimate tensile strength (UTS) and elongation ( $\delta$ ) of the as-cast alloys at RT are shown in Fig. (6). It can be seen that addition Ti element improves the mechanical properties of alloys. When $\mathrm{Ti}$ additions are 0.4 (wt\%), the AZ91-0.4Ti alloy exhibits highest UTS and $\delta$ in the system alloys, the values are $197 \mathrm{MPa}, 6.9 \%$ respectively. However, if the Ti contents are above $0.4(\mathrm{wt} \%)$, the ultimate tensile strength and the elongation reduce. The tensile results demonstrate that the influence of $\mathrm{Ti}$ element addition in metal on tensile properties was significant. After Ti elements addition in alloy, the size of grain becomes small, grain boundaries increasing, and the quantity of $\beta$ phases is few or disperses. For these reasons, the crack tendency is reduced, fracture growth is slowed down, and thus the tensile strength has the enhancement. The addition of $\mathrm{Ti}$ element improves the mechanical properties by refining and diapering $\beta$ phases. Diffuse distribution of $\beta$ phases can reduce the fragmentation action on the matrix and the weakening of the role of grain boundary. The mobility of the grain boundary and dislocation slip were greatly enhanced because of refining the $\beta$ phases. so the plasticity of AZ91-Ti alloy has been enhanced. However, if the Ti contents are above $0.4(\mathrm{wt} \%)$, thick $\mathrm{TiAl}_{3}$ will solid and gather at the crystal boundary place to destroy the connection between the crystal grain and the crystal grain. That causes the alloy at time of stretching easily to crack in crystal boundary place, finally, the elongation ratio and the ensile strength of the AZ91Ti magnesium alloy are reduced, Even lower than the performance of the original alloy.

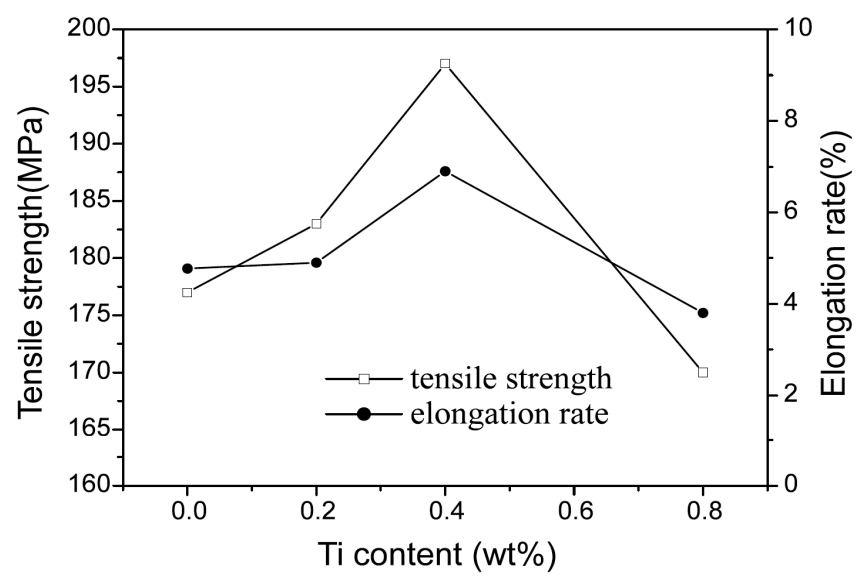

Fig. (6). Mechanical properties of different Ti contents testing alloys.

The fractured surfaces of AZ91-Ti alloy are shown in Fig. (7). It shows brittle fracture feature in which quasicleavage is the main characteristic with obvious quasicleavage steps and tearing ridges.

Fig. (8) is the EDS analysis of tearing ridge and crack respectively. Comparison of Fig. (8a, b), it can be seen that the ingredient of tearing ridge is mainly $\mathrm{Mg}$ and $\mathrm{Al}$ element (spectrum1), moreover their atomic ratio is 9:1. On the crack (spectrum2), there are not only $\mathrm{Mg}, \mathrm{Al}$ element, but also $\mathrm{Zn}$ element appear. However, the amount of $\mathrm{Zn}$ is small, this indicated that pit area is $\alpha-\mathrm{Mg}$ solid solution with $\mathrm{Zn}$ atoms, this also shows the crack has been extended into the $\alpha-M g$ grains. Basing on the EDS analysis to the different position on fracture, it may be obtained that tearing ridges embolden the breaks of $\beta$ phases. When the Ti contents are 0.4 (wt\%), the fractures of the alloys were showed tearing ridges clearly, shorter than $0.2(\mathrm{wt} \%) \mathrm{Ti}$, a few circular dimples appear locally, and the characteristics of quasi-cleavage and ductile fracture form as shown in Fig. (7b). From the results of above analysis, the plasticity of the alloys can be enhanced obviously when the Ti contents are $0.4(\mathrm{wt} \%)$. 

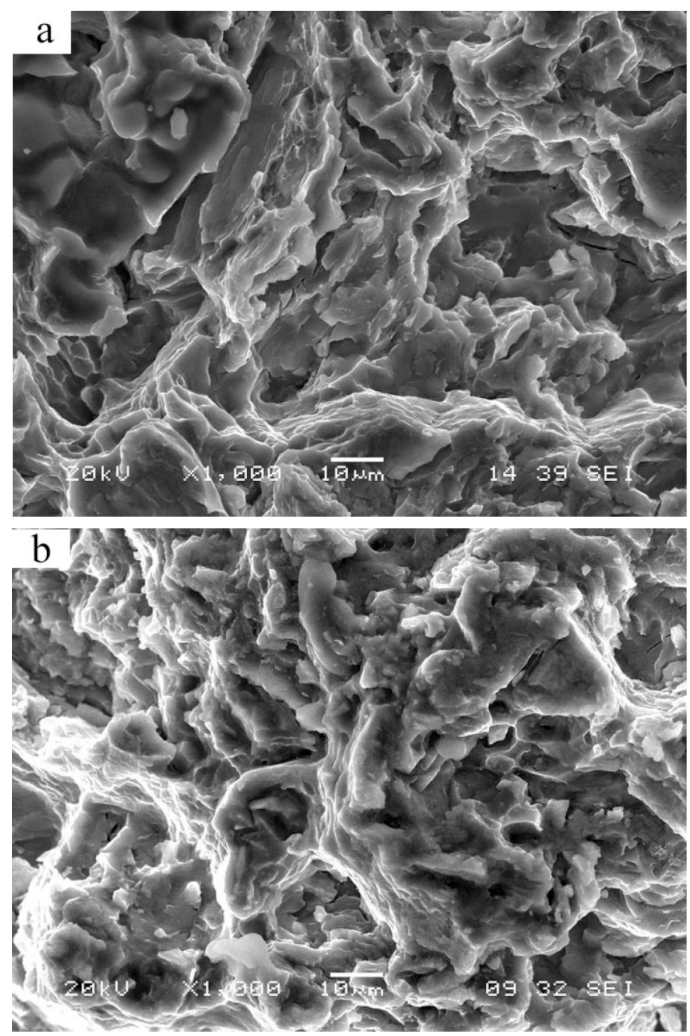

Fig. (7). Fracture morphologies of AZ91 alloy at different Ti content: a) $0.2 \mathrm{Ti}$; b) $0.4 \mathrm{Ti}$.
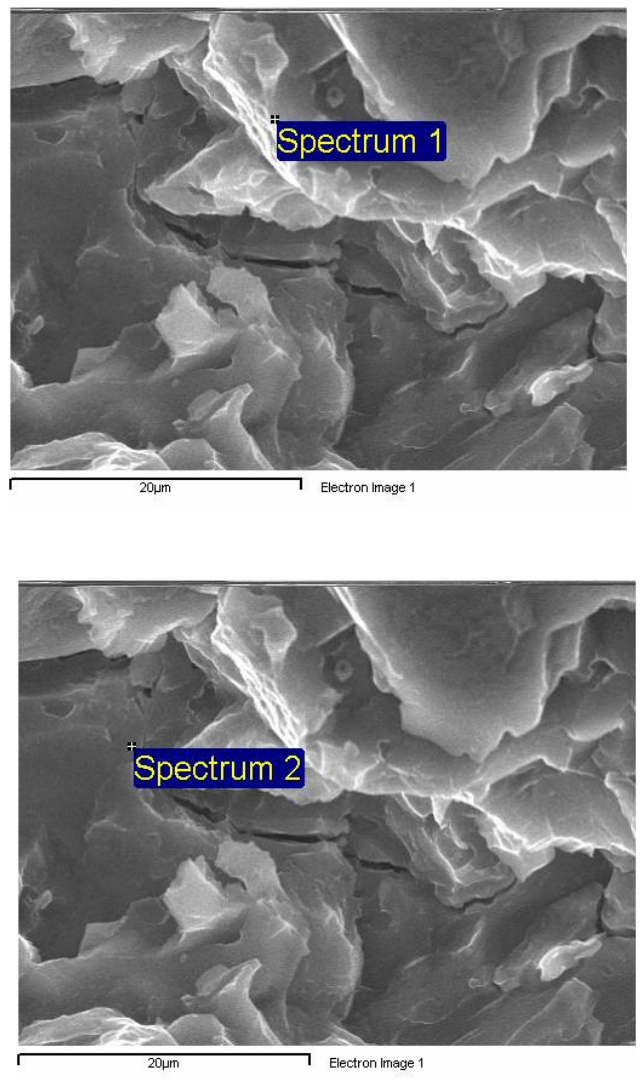

Fig. (8). EDS of AZ91-0.4Ti magnesium alloy.

\subsection{Corrosion}

\subsubsection{Effect of Ti Element Addition Content on Corrosion Rates}

Fig. (9) illustrates the corrosion rate of AZ91-XTi alloys in the solution of $3.5 \% \mathrm{NaCl}$ by static weight loss method. From Fig. (9) it can be seen that the corrosion rate of AZ91 alloy rapidly increased with prolonging corrosion time, and the value of corrosion rate was relatively larger. The addition of Ti remarkably reduces the corrosion rate of AZ91 alloy, and corrosion rate of alloy with $0.8(\mathrm{wt} \%) \mathrm{Ti}$ is minimum value. At the initial stage of corrosion, the corrosion rate of the three alloys with various Ti contents is low, and with corrosion time prolonging, corrosion rate enhances obviously. The corrosion rate of three alloys containing $\mathrm{Ti}$ exhibits alternate increasing and decreasing.

In addition, it can be found that, under the same conditions, the corrosion rate of alloys reduced with increasing Ti contents and reached minimum in the case of $0.8(\mathrm{wt} \%) \mathrm{Ti}$. The corrision rate of AZ91-0.4Ti alloy is higher than the AZ91-0.8Ti. This phenomenon is proposed to attribute to two kinds of reasons: appearance of pitting corrosion owing to the existence of active anion $\mathrm{Cl}^{-}$, as well as the formation of surface oxide film and thickening. The effect of $\mathrm{Cl}^{-}$gradually reduced with the thickening of surface film, so over a certain time the corrosion rate began declining. Besides the anode dissolved in the process of electrochemical reaction with increasing corrosion time, sapping appeared at some location and resulted in the abscission of the undissolved metallic particles. In this case,

(a) EDS of rearing ridge

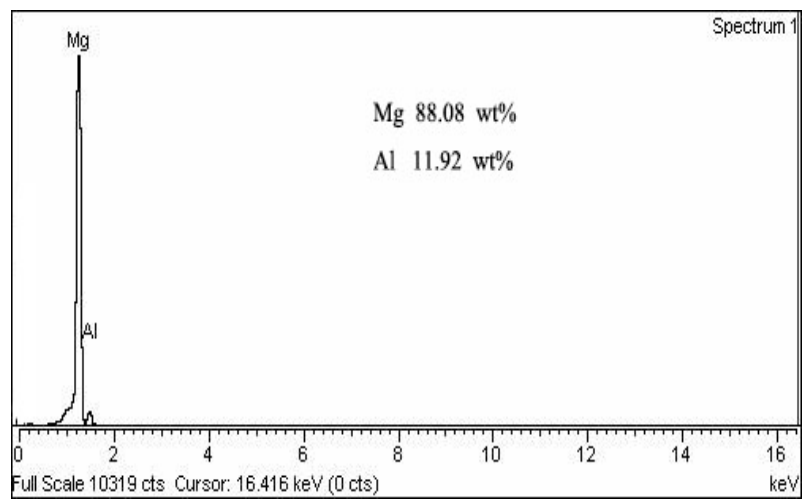

(b) the EDS of crack

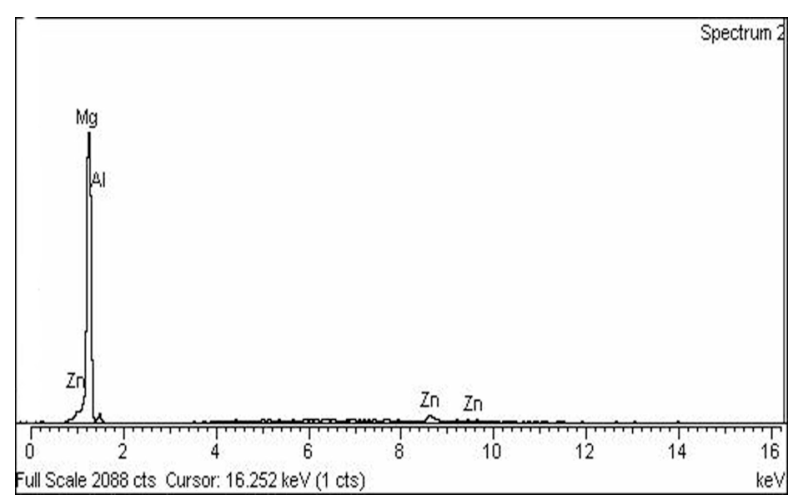


the corrosion rate tested by the weight loss method would increase. The pitting action above mentioned intensified dued to the large amount of $\mathrm{Cl}^{-}$in the solution of $3.5 \% \mathrm{NaCl}$. Therefore, the corrosion rate exhibited rapid increasing. But subsequent thickening of surface film could prevent the function of $\mathrm{Cl}^{-}$and decline the corrosion rate. For the various alloys with $\mathrm{Ti}$ declining time of corrosion rate were also different, such as immersed after 5 day for AZ91-0.2Ti alloy, while immersed after 3 day for AZ91-0.4Ti and 4day for AZ91-0. 8Ti alloy, which were related to theirs thickening rate of surface film. During the whole corrosion process, the

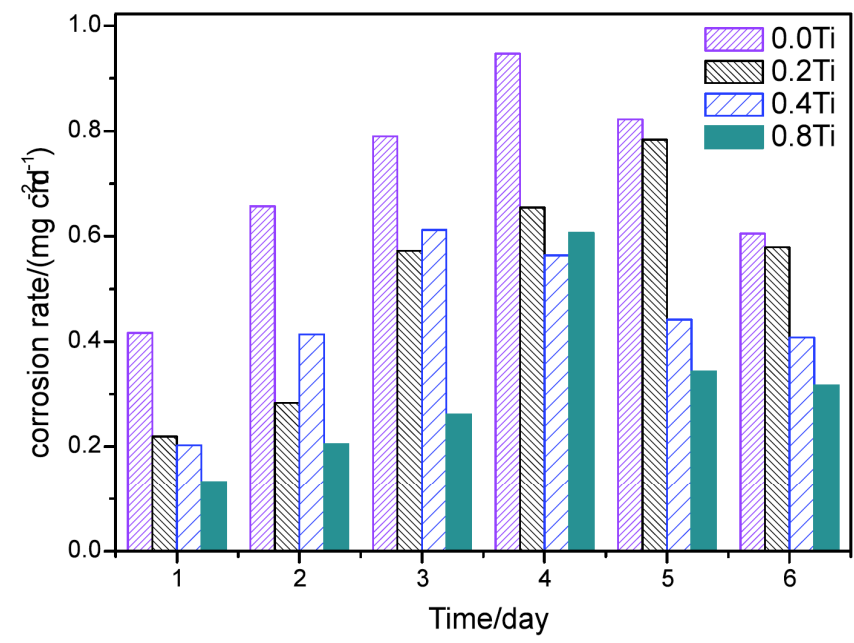

Fig. (9). Corrosion rate of AZ91-XTi as-cast alloy in 3. 5\% $\mathrm{NaCl}$ aqueous solution.

thickening of surface film and pitting action of $\mathrm{Cl}^{-}$were alternately dominant. The pitting corrosion started immediately and then destroyed the formation of surface film when immersed into the corrosion medium of 3. 5\% $\mathrm{NaCl}$. So the corrosion rate increased continuously until $4^{\text {th }}$ day, the alloys were followed by declining tend, which was probably caused by accumulation of corrosion products on the surface.

Fig. (10) shows the surface micrographs of AZ91 and AZ91-0.8Ti alloy immersed in corrosion medium of 3. 5\% $\mathrm{NaCl}$ for 6 day. It can be found that AZ91 alloy was corroded seriously and lost brightness, even whole surface was corroded and corrosion extended towards interior. The dark areas are the corrosion hollows after the falling-off of corrosion products, as shown in Fig. (10a). Fig. (10b) shows small amount of pitting corrosion produced on the surface of AZ91-0.8Ti alloy and still keeping certain brightness under the same conditions. The micromorphologies of corrosion surface show the addition of Ti elements might remarkably increase corrosion resistance of AZ91 matrix alloy.

The corrosion performance of AZ91-XTi alloy depends on the integrated influence of the $\mathrm{A} 1$ content in $\alpha-\mathrm{Mg}$ matrix and the $\beta$ phase barriers. It is knew the corrosion usually appeared in the interior of $\alpha-\mathrm{Mg}$ grain for AZ91 alloy at the early stage while less corroded at the grain boundary. According to the study [15], higher Al element content in the matrix could effectively depress the corrosion. In as-cast microstructure, Al elements mostly resist in the boundary of $\beta$ phases, after having added Ti element into AZ91 alloy, the amount of $\beta$ phases are low, Al content in $\alpha$-Mg matrix are high. $\beta$ phases as the reinforcing phases in AZ91 alloy play a significant role during the corrosion, especially the content and distributions of $\beta$ phases. If $\beta$ phases non-uniformly distribute (Figs. 1, 2), the barrier effects of $\beta$ phases will reduce even disappear. On the other hand, if $\beta$ phases uniformly distribute (Fig. 3), then $\beta$ phases, corrosion products and $\mathrm{TiAl}_{3}$ intermetallics (Fig. 4) may act as barrier to prevent corrosion and decrease the corrosion rate of alloys. So addition Ti element results in the massive of netlike $\beta$ phases transformed into discontinuous netlike or dispersed the fine particle and uniformly distributed are advantageous to exert barrier effect of $\beta$ phases. A lower amount of cathodic $\beta$ phases and higher Al content matrix alloy prevent severe corrosion attack. Therefore the result shows the best corrosion resistance for AZ91-xTi alloy.

\subsubsection{Effect of Ti Element Addition Content on Electrochemical Behavior}

The potentiodynamic polarization curves of different $\mathrm{Ti}$ addition content AZ91 alloys in $3.5 \% \mathrm{NaCl}$ solution are shown in Fig. (11). From Fig. (11) it can be seen that balance potential and corrosion potential of alloys with small content Ti addition can move towards positive direction compared with AZ91 matrix alloy. Namely adding 0.4 (wt\%) Ti may
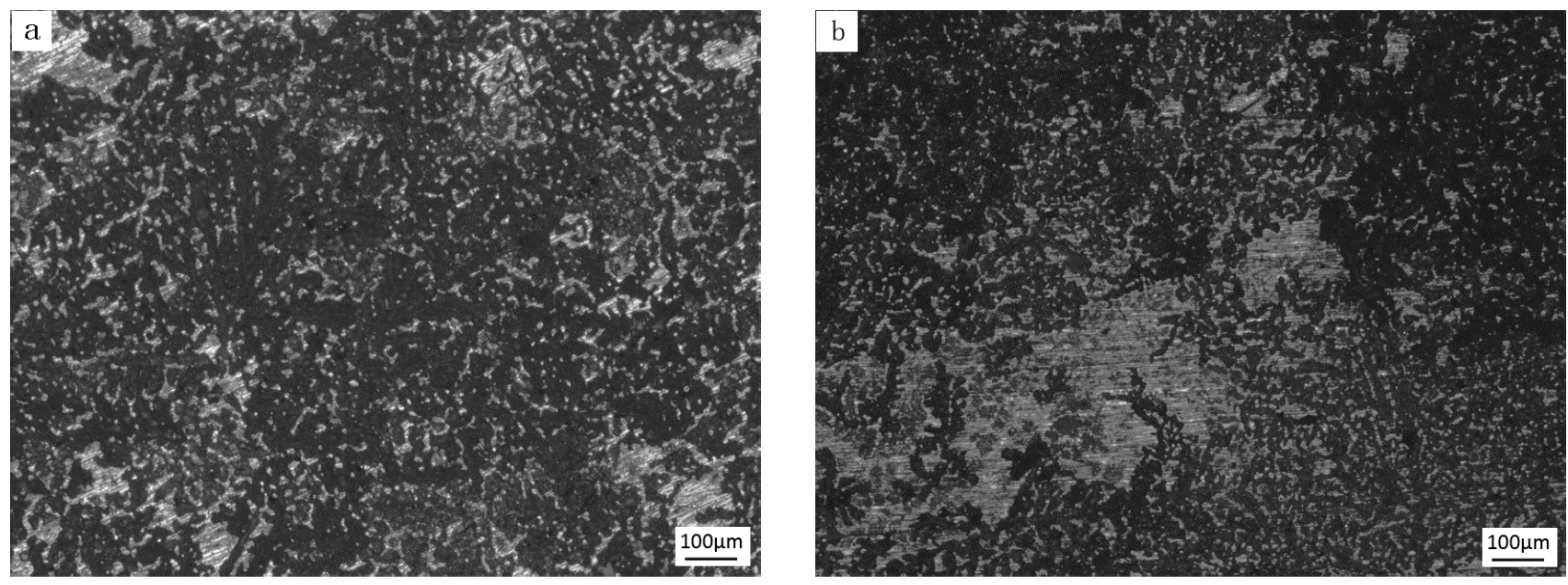

Fig. (10). Surface corrosion micrographs of AZ91 (a) and AZ91-0. 8Ti (b) as-cast alloy immersed in the solution of $3.5 \% \mathrm{NaCl}$ for 6 day. 
increase potential of alloy and decrease corrosion current density, which is advantageous to improve the corrosion resistance of alloys.

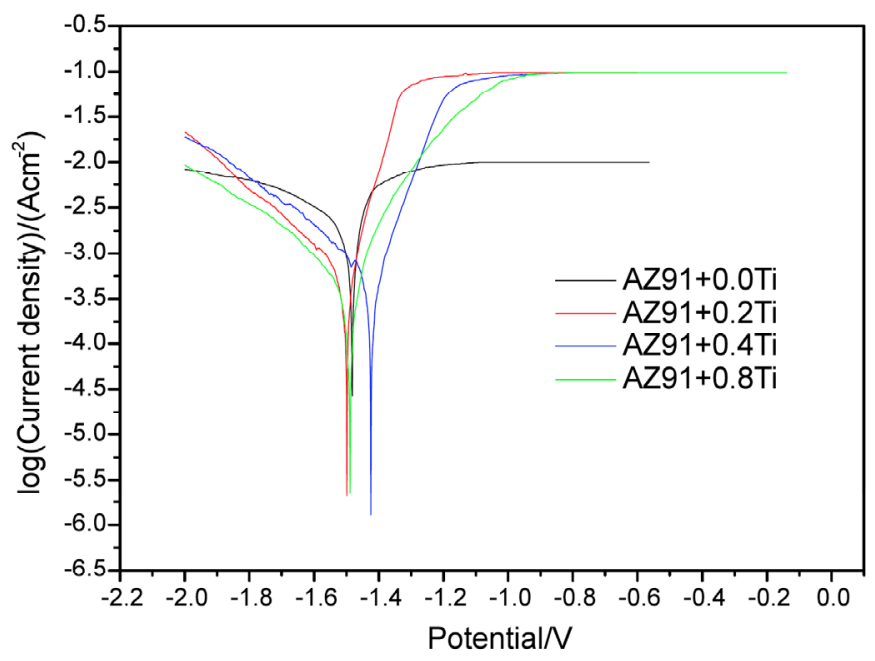

Fig. (11). Polarization curves for as-cast alloys as a function of $\mathrm{Ti}$ content.

When Ti addition content is 0.8 (wt $\%$ ), Tafel curve move towards negative direction. The Tafel fitting results based on the polarization curves in Fig. (11) are presented in Table 3, which reveals that the addition of Ti may increase the balance potential and corrosion potential of AZ91 alloy and also decrease current density about one order of magnitude. According to Faraday's law, the corrosion rate is direct proportion to current density [16,17], thus it can be concluded that the poor corrosion resistance of AZ91alloy may significantly be improved after adding $0.4(\mathrm{wt} \%) \mathrm{Ti}$ in present work.

Table 3. Tafel Fitting Results Based on Polarization Curves of AZ91-xTi Alloys

\begin{tabular}{|c|c|c|c|}
\hline Alloy & $\begin{array}{c}\text { Ecorr1 } \\
\text { (Balance } \\
\text { Potential)/V }\end{array}$ & $\begin{array}{c}\text { Ecorr2 } \\
\text { (Corrosion } \\
\text { Potential) } / \mathbf{V}\end{array}$ & $\begin{array}{c}\text { Icorr } \\
\text { (Corrosion Current)/ } \\
\text { logAcm }^{-2}\end{array}$ \\
\hline \hline AZ91-0.0Ti & -1.4793 & -1.576 & -2.497 \\
\hline AZ91-0.2Ti & -1.5006 & -1.489 & -3.302 \\
\hline AZ91-0.4Ti & -1.4254 & -1.406 & -3.268 \\
\hline AZ91-0.8Ti & -1.4862 & -1.543 & -3.160 \\
\hline
\end{tabular}

The $\beta$ phase are known to play a dual role in corrosion processes of magnesium alloys $[15,18]$. On the one hand, $\beta$ phases themselves have a high resistance to corrosion, so they may play the role of reducing corrosion rate by forming a barrier. Once the less noble phases are dissolved [19-21], the size and morphology of $\beta$ phases have significant influence on corrosion behavior of AZ91 alloy. On the other hand, $\beta$ phases are highly cathodic to the matrix and they can thus act as an effective cathode to cause galvanic corrosion, $\alpha-\mathrm{Mg}$ as anode [15]. The main reason for the discrepancy between the electrochemical behavior and weight loss corrosion rate is that the inhibiting effect of the $\beta$ phases in the AZ91-Ti alloy predominated during short interval of electrochemical testing but the accelerating effect of the decreasing of $\mathrm{Al}$ contents in the matrix predominated in the long period immersion testing.

\section{CONCLUSION}

(i) The addition of Ti element in the AZ91 alloy can not only reduce the grain size of the as-cast alloy, but also form the metallic compounds which can increase the relative proportion of $\alpha-\mathrm{Mg}$ phase and reduce the relative proportion of $\beta-\mathrm{Mg}_{17} \mathrm{Al}_{12}$ phases.

(ii) The morphology of $\beta$ phases in AZ9-XTi alloy is changed from coarse, uneven, semi-continuous skeletal network to small, uniform, short rod-like or granular due to Ti addition.

(iii) Small amount of Ti addition to the AZ91 alloy result in significant refinement of microstructure and improvement of tensile properties. When the content of Ti elements are $0.4(\mathrm{wt} \%)$, the values of tensile strength and elongation are up to a maximum value of $197 \mathrm{MPa}$ and $6.9 \%$, respectively.

(iv) Addition of Ti may remarkably reduce the corrosion rate and corrosion current of AZ91 alloy, in the case of AZ91-0.8Ti alloy has minimum corrosion rate value, AZ91-0.4Ti alloy has minimum corrosion current density in present work.

(v) The main reasons of corrosion resistant of AZ91-xTi alloy improved are grain refined and $\beta$ phases changed to small, uniformly distribution.

\section{ACKNOWLEDGEMENTS}

Declared none.

\section{CONFLICT OF INTEREST}

Declared none.

\section{REFERENCES}

[1] Xiaoling X, Ping L, Jiangwen L, Dongxiao W, Jianfen N, Muddle BC. Structure of hcp/bcc Inter-Phase Boundaries in AZ91 Mg-Al Alloy. Chin J Nonferrous Met 2003; 13: 15-20.

[2] Regev M, Aghion E, Rosen A. Creep studies of AZ91D pressure die casting. Mater Sci Eng 2001; A234-236: 46-50.

[3] Song G, Atrens A. Understanding magnesium corrosion - a framework for improved alloy performance. Adv Eng Mater 2003; 5: 837-58.

[4] Winzer N, Atrens A, Song G, et al. A critical review of the stress corrosion cracking (SCC) of magnesium alloys. Adv Eng Mater 2005; 7: 659-93.

[5] Song G, Atrens A, Dargusch M. Influence of microstructure on the corrosion of diecast AZ91D. Corrosion Sci 1998; 41: 249-73.

[6] Ambat R, Aung NN, Zhou W. Evaluation of microstructural effects on corrosion behaviour of AZ91D magnesium alloy. Corros Sci 2000; 42: 1433-55.

[7] Minmin W, Yongqing Z, Lian Z. Factor analysis on creep behavior of titanium alloys. Rare Met Mater Eng 2002; 31: 135-9.

[8] Nair KS, Mittal MC. Rare earths in magnesium alloys. Mater Sci Forum 1988; 30: 89.

[9] Guang-yin Y, Yang-shan S, Wei-min Z, Jian-rong S. Tensile and creep properties of Mg-9Al based alloys containing bismuth. Trans Nonferrous Met Soc Chin 2000; 10: 469.

[10] Sun Y, Zhang WM, Min XG. Tensile strength and creep resistance of Mg-9Al-1Zn based alloys with calcium addition. Acta Metal Sin 2001; 14: 253 .

[11] Min XG, Sun YS, Xue F, et al. Effect of Ca on microstructure and tensile strength of AZ91 alloys. J Mater Sci Technol 2002; 10: 93.

[12] Mo W, Deng GZ, Luo FC, et al. Titanium metallurgy. Beijing: Metallurgy Industry Press 1998; pp. 97-9. 
[13] Liang Y, Chen YM. Thermodynamic manual book of inorganic matter. New England: Northeast University Press 1993; p. 83.

[14] Lathabai S, Lloyd PG. The effect of scandium on the microstructure, mechanical properties and weldability of a cast AlMg alloy. Acta Mater 2002; 50: 4275-92.

[15] Ambat R, Aung NN, Zhou W. Evaluation of microstructural effects on corrosion behaviour of AZ91D magnesium alloy. Corros Sci 2000; 42: 1433-55.

[16] Zhang ZM. Metallic Corrosion. Beijing: Metallurgical Industry Press 1993; p. 55 (in Chinese).

[17] Song G, Atrens A, St John D, Wu X, Nairn J. The anodic dissolution of magnesium in chloride and sulphate solutions. Corros Sci 1997; 39: 1981-2004.
[18] Mathieu S, Rapin C, Hazan J, Steinmetz P. Corrosion behaviour of high pressure die-cast and semi-solid cast AZ91D alloys. Corros Sci 2002; 44: 2737-56.

[19] Crawley AF, Milliken KS. Precipitate morphology and orientation relationships in an aged $\mathrm{Mg}-9 \% \mathrm{Al}-1 \% \mathrm{Zn}-0.3 \% \mathrm{Mn}$ alloy. Acta Metall 1974; 22: 557-62.

[20] Lunder O, Lein JE, Aune TK, Nisancioglu K. The role of Mg17A112 phase in the corrosion of Mg Alloy AZ91. Corrosion 1989; 45: 741 .

[21] Uzan P, Frumin N, Eliezer D, Aghion E, Eliezer D, Eds. Magnesium Science and Technology. Proceedings of the $2^{\text {nd }}$ Israeli International Conference. Dead Sea: Israel. Feb 2000; p. 285.

(C) Ai and Quan; Licensee Bentham Open.

This is an open access article licensed under the terms of the Creative Commons Attribution Non-Commercial License (http://creativecommons.org/licenses/by-nc/3.0/) which permits unrestricted, non-commercial use, distribution and reproduction in any medium, provided the work is properly cited. 